\title{
Methods of optimization of motor transportation processes
}

\author{
Alexey Terentyev ${ }^{1 *}$, Sergey Evtyukov ${ }^{2}$, and Maria Karelina ${ }^{1}$ \\ ${ }^{1}$ Moscow Automobile and Road Construction State Technical University (MADI), 125319 Moscow, \\ Russia \\ ${ }^{2}$ Saint Petersburg State University of Architecture and Civil Engineering, 190005 Saint Petersburg, \\ Russia
}

\begin{abstract}
A scientific approach to the methods of technical support, economic and organizational management, planning and control of the operation of cars often dictates the need to make a decision, not one at a time, but several efficiency measures. The article outlines the approach to the solution of multicriteria transportation problems based on the methods of regionalization according to the principle of observing the hierarchical correlation of probabilities of possible states of the external environment.
\end{abstract}

\section{Introduction}

Scientific approach to methods of technical providing, economic and organizational management, planning and control of processes of operation of cars quite often dictates need to make the decision not on one, and at once on several indicators of efficiency. Such tasks are multicriteria. Development of quantitative recommendations in multicriteria situations is connected with considerable difficulties which have objective character. However, level modern practical motor transportation (etc. the industries) tasks demands to make decisions in the conditions of a multicriteria. Moreover, one-criteria situations in most cases artificially receive from multicriteria.

\section{Material and methods}

In this regard development of the methods of vector optimization aimed at finding optimal or reasonable solutions multicriteria tasks [1-6] is intensively conducted now. In works [612] the campaign to the solution of multicriteria motor transportation tasks the cornerstone of which it is stated the division into districts method by the principle of observance of a hierarchical ratio of probabilities of possible conditions of the external environment is. Briefly we will give its basic provisions and an example with the set basic data. Briefly we will give its basic provisions and an example with the set basic data.

Any problem of optimization of the made decision is characterized by three basic concepts: set of possible decisions $m$; a set of types of a condition of the environment $n$ and

\footnotetext{
*Corresponding author: aleksej.terentev.67@bk.ru
} 
$a_{i j}$ corresponding to them efficiency of decisions. The matrix of effectiveness of different actions at different conditions of the environment has an appearance:

$$
\left\|a_{i j}\right\|=\left(\begin{array}{cccc}
a_{11} & a_{12} & \ldots & a_{1 n} \\
a_{21} & a_{22} & \ldots & a_{2 n} \\
\ldots & \ldots & \ldots & \ldots \\
a_{m 1} & a_{m 2} & \ldots & a_{m n}
\end{array}\right),
$$

\section{Theory}

We will give a matrix of basic data:

$$
A=\left(\begin{array}{ccc}
0,20 & 0,24 & 0,22 \\
0,76 & 0,18 & 0,34 \\
0,18 & 0,80 & 0,26 \\
0,84 & 0,02 & 0,46
\end{array}\right) .
$$

We will formulate basic provisions of a method a division into districts method by the principle of observance of a hierarchical ratio of probabilities of possible conditions of the external environment [13-15]:

- division into districts is made not by the principle of domination of separate actions, and by the principle of preservation of the set hierarchical ratio of possible conditions of the environment.

- upon transition from a multicriteria task to theory tasks of "games with the nature" probabilities of conditions of the nature (environment) of $p_{j}$ on sense are adequate to coefficients of relative importance of criteria $c_{j}, p_{j} \equiv c_{j}$.

According to point 1 , distribution of coefficients of relative importance of criteria of efficiency is subordinated to restrictions:

$$
0 \leq c_{j} \leq 1, \quad j=\overline{1, n}, \sum_{j=1}^{n} c_{j}=1,
$$

Values of coefficients $c_{i}$, aren't specified. However, most often, depending on character of an objective, there are bases for an arrangement of these coefficients in the sequence at which type conditions are satisfied

$$
c_{1} \geq c_{2} \geq \ldots \geq c_{i} \geq \ldots \geq c_{m-1} \geq c_{m}
$$

The total quantity of the sequences of this kind for distributions of system is defined by the number of shifts of $P_{m}=m !$. At $m=3$ the field of distributions of coefficients of relative importance degenerates in a rectangular triangle with single legs. The division into districts method algorithm by the principle of observance of a hierarchical ratio of probabilities of possible conditions of the external environment for the choice of an optimal variant of the required decision is implemented as follows:

- relative importance of indicators of $c_{j}$, are arranged in the form of the sequence (3);

- for each compared option $i$ the problem of linear programming is solved: 


$$
\left\{\begin{array}{l}
D_{i}=\sum_{j=1}^{n} a_{i j} c_{j} \rightarrow \max \\
\sum_{j=1}^{n} c_{j}=1,0 \leq c_{j} \leq 1, c_{j} \geq c_{j+1}, i=\overline{1, n-1}
\end{array}\right.
$$

\section{Results}

Analytical decision

$$
c_{j}=\left\{\begin{array}{l}
\frac{1}{k}, \text { if } j \leq k, \\
0, \text { if } j>k,
\end{array}\right.
$$

where the index $k$ is defined from a condition. $a_{k j}=\max a_{i j}$.

\section{Discussion}

Fundamental difference of the developed method is the lack of the formalized communication between coefficients of relative importance by separate criteria [16-18]. We will provide the graphic solution of an example at $n=3$ in comparison with a division into districts method by the principle of domination of separate actions. The field of distributions of coefficients of relative importance degenerates in a rectangular triangle with single legs (figure 1).

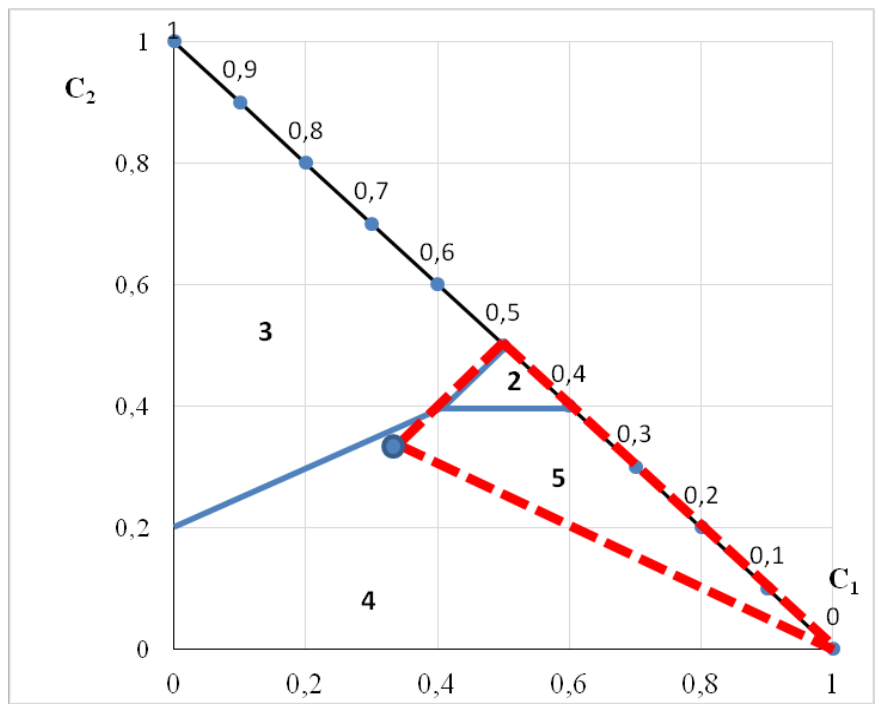

Fig. 1. Graphic solution of an example:

2, 3 and 4 - areas of probability of availability of efficiency of the decision at application of a method division into districts by the principle of domination of separate actions; 5 - area of probabilities of efficiency at application of a method division into districts by the principle of preservation of the set hierarchical ratio of possible conditions of the environment (for $\mathrm{n}=3$ ).

Analyzing methods of division into districts it is easy to be convinced that the area of all possible decisions (at $n=3$ ) by each version of the decision is the plane, and crossing of the planes of efficiency according to each decision are projected in the line of demarcation of 
areas of domination of decisions in the field of distributions of coefficients of relative importance (figure 2). Feature of application of a method division into districts by the principle of preservation of the set hierarchical ratio of possible conditions of the external environment (the problem of linear programming is solved it is solved on max) is obtaining the decision at the maximum domination of the criterion established by a priority $[3,19,20]$.

For the reviewed example the matrix of coefficients of relative importance takes a form.

$$
c_{i j}=\left(\begin{array}{ccc}
0,5 & 0,5 & 0 \\
1 & 0 & 0 \\
0,5 & 0,5 & 0 \\
1 & 0 & 0
\end{array}\right) .
$$

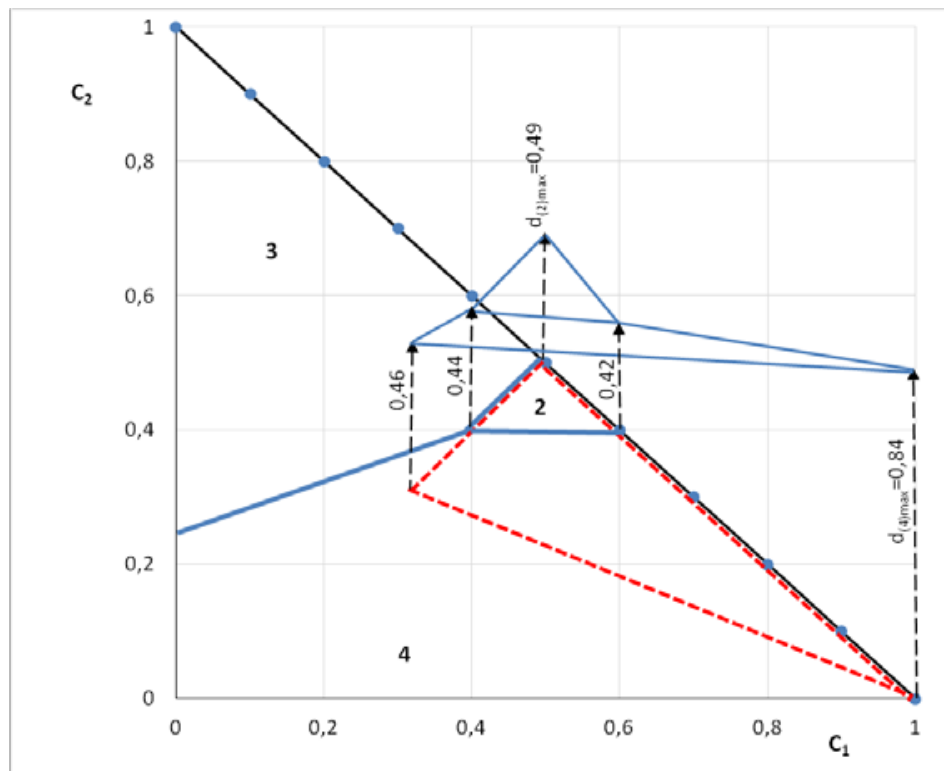

Fig. 2. Graphic solution of an example:

$\mathrm{d}(4) \max =0,84$ and $\mathrm{d}(2) \max =0,49$ - the greatest possible decisions on the fourth and second option of actions respectively; $0,42,0,44$ and 0,46 - frequent cases of efficiency of decisions.

For the reviewed example the matrix of coefficients of relative importance takes a form.

$$
c_{i j}=\left(\begin{array}{ccc}
0,5 & 0,5 & 0 \\
1 & 0 & 0 \\
0,5 & 0,5 & 0 \\
1 & 0 & 0
\end{array}\right) .
$$

We will note that in practice of activity of ATP depending on the nature of the performed works, a type of the transported load, etc., as a rule, there is not only an obligatory priority of several criteria, but also need to receive differentiable values of coefficients of relative importance on the set efficiency level. For example, when it is necessary to implement a number of actions at the same time, each of which is defined by a complex of own indicators and at the same time optimum distribution of resources (personnel, production capacities, finance, etc.) to their implementation is required. In this case it is required to receive more balanced values of coefficients of relative importance according to the purposes of the 
general strategy of the studied system. Then the decision [5] is transformed by introduction of value of extent of domination of criteria $-\lambda$.

$$
\lambda=\frac{n-1}{n} .
$$

\section{Conclusion}

This modernization of a method division into districts will allow to determine values of coefficients of relative importance of decisions in multicriteria tasks in compliance by the principle of preservation of the set hierarchical ratio of possible conditions of the nature by real operating conditions of the studied system.

\section{References}

1. C.A. Evtyukovof, A.V. Terentyev, G. Ginzburg, Methodology of management of rational life cycle of the car, World of transport and technological machines, 1 (56), pp. 3-10 (2017)

2. D.S. Lobaryov, A multicriteria dynamic task with expert estimates. Young scientist, 11 (1), pp. 32-37 (2010)

3. I.L. Makarova, The analysis of methods of definition of weighting coefficients in an integral indicator of public health, International magazine "nauki Simvol", 7, (2015)

4. Front sights E., Müller, P. Methods of acceptance of technical solutions: Transfer from German - M.: Meath,.-208 pages. (1990)

5. T. Saati, Decision-making at dependences and feedback: analytical networks. M.: Book house of "LIBROKOM", 360 pages (2009)

6. H.A. Taha, Introduction to a research of operations, 7th edition: The lane with English - M.: Williams publishing house, 912 pages (2005)

7. A.V. Terentyev, Development of a method of division into districts. Materials of the 4th international scientific and practical conference. Innovations on transport and in mechanical engineering. - SPb.: National mineral and raw university "Gorny", Page 127-130 (2016)

8. A.V. Terentyev, B.D. Prudovsky, Methods of definition of a great number of Pareto in some problems of linear programming, Notes of Mining institute. Volume 211. - SPb.: National mineral and raw university "Gorny", Page 89-90 (2015)

9. A.V. Terentyev, Multicriteria indicator of quality of the car. Messenger of civil engineers. SPb: SPbGASU 2015, 1(48), Page 201-204 (2015)

10. A.N. Tikhomirova, E.V. Sidorenko, Modification of a method of the analysis of hierarchies of $T$. Saati for calculation of scales of criteria at assessment of the innovation projects. Modern problems of science and education, 2 (2012)

11. N.V. Hovanov, Yu.V. Fedotov, Model of accounting of uncertainty at creation of summary indicators of efficiency of activity of complex production systems. Scientific reports No. 28(R) - 2006, Publishing house of SPb.: Scientific research institute of management of St.Petersburg State University, 37 pages (2006)

12. A.V. Parkhomenko, L.V. Parkhomenko, B.I. Gerasimov, Economic-mathematical models of controlling at the industrial enterprise. Tambov: Publishing house Tambov state technical university, 96 pages (2005) 
13. B.D. Prudovskiy, A.V. Terentiev, Investigation methods for "current repairs labourintensiveness" factor for a vehicle. Life Science Journal, 11 (10s), pp. 307-310 (2014)

14. A.V. Terentiev, T.A. Menukhova, Economics and society in the era of technological changes and globalization the methodology of the operating cost accounting in identifying mileage of efficient motor vehicle operation. International Journal of Economics and Financial Issues, 5 (3S), pp. 183-186 (2015)

15. A. Kapustin, A. Terentiev, Rational Lifetime of a Vehicle in Terms of Ensuring Security of Its Design. Transportation Research Procedia, 20, pp. 254 - 260. (2017)

16. E. Mushik, P. Mueller, Methods of making technical decisions, Translation from German, Moscow: Mir, 208 p. (1990)

17. S. Zhankaziev, Current trends of road-traffic infrastructure development. Transportation Research Procedia. "12th International Conference "Organization and Traffic Safety Management in Large Cities", SPbOTSIC 2016" 28-30 September 2016, St. Petersburg, Russia. P. 731-739 (2016)

18. A Plotnikov, Y Kotikov, P Kravcenko, Classification Investigations of Traffic Management Schemes Having Conflict Loading at the Signal-Controlled Road Junctions. Transportation Research Procedia, P. 511- 515 (2017).

19. M. Kerimov, R. Safiullin, A. Marusin, A. Marusin, Evaluation of Functional Efficiency of Automated Traffic Enforcement Systems, 12th International Conference «Organization and Traffic Safety Management in Large Cities», SPbOTSIC-2016, 2830 September Transportation Research Procedia (2016), St. Petersburg, Russia. pp. 288-294 (2016)

20. G.-Y. Wang, Q.-S. Chen, J. Wang, Discussion on the Intelligent Vehicle Technologies. Computer Science, 39 (5), pp. 1-8 (2012) 